\title{
DE ECONOMISCHE TOESTAND VAN SURINAME
}

$$
\text { DOoR }
$$

\author{
L. C. PREY
}

Onder bovenstaanden titel werden in de Econ. Statistische berichten van 10 en 17 Mei j.1. door den heer Mr. A. van Traa eenige beschouwingen gegeven aan de hand van de cijfers, voorkomende in het overzicht van 's Lands financien, als bijlage gevoegd bij de Surinaamsche begrooting 1934. Staat IV dezer bijlage geeft n.l. een overzicht van de ontvangsten en van de zuivere uitgaven t.w. de uitgaven na aftrek van de rechtstreeks tegenover de brutouitgaven staande ontvangsten, terwijl Staat II dezer bijlage aangeeft, wat het Land ontvangt voor verleende diensten en uit de exploitatie van bedrijven, zooals vervoer te land, te water, post, telegrafie enz.

Daarvan wordt nu door Mr. van Traa gezegd:

„Beide groepen van cijfers kunnen ons, elk op zich zelf, een in„zicht geven in de economische ontwikkeling over een reeks van „jaren. Bezien wij nu Staat IV, dan vinden wij, dat de totale ont„vangsten uit belastingen en andere middelen, dus de inkomsten ,als Overheid, in 1920 bedroegen $f 3.507 .707$, in $1925 f 3.579 .792$, ,in $1930 f 3.320 .132$, terwijl zij volgens de voorloopige cijfers in „1932 nog slechts $f 2.766 .743$ bedroegen.

„Bij oppervlakkige beschouwing kan men van deze cijfers den „indruk krijgen, dat de inkomsten zich vrij constant hebben ge„houden en eerst onder den invloed van de crisis een ongunstig „verloop hebben genomen. Doch wanneer men de cijfers der in„komsten over de tusschenliggende jaren 1925 tot 1930 raad„pleegt, zal men zien, dat reeds in 1927 een scherpe daling ver„geleken met 1926 is ingetreden en dat in 1928 en 1929 de ont„vangsten reeds ruim $f 100.000$ respectievelijk $f 175.000$ lager „waren dan in 1920. En geheel anders wordt de indruk, wanneer "men rekening houdt met de omstandigheid, dat de bevolking „van 107.000 zielen in 1920 toenam tot 136.000 eind 1931 en dat „alle belastingen sedert 1920 verhoogd zijn. Want dan blijkt, 
„dat het natuurlijk accrès dat als gevolg van deze beide factoren „had kunnen worden verwacht, niet alleen is uitgebleven, doch „zelfs plaats heeft moeten maken voor een absolute daling der „inkomsten."

Aan het volgen van den door schrijver gekozen weg zijn gevaren verbonden. Niet wanneer de conclusies betreffen de bloote cijfers, ter bepaling van een eventueel tekort of een teveel, maar wel wanneer die conclusies komen op het terrein van de economische ontwikkeling, want dan dient men die cijfers te ontleden en na te gaan, uit welke factoren zij zijn opgebouwd. Doet men dit, dan ziet men, dat wat de „Belastingen” betreft, de uitkomsten in de jaren 1920 t/m 1926 onder den invloed stonden van buitengewone heffingen, die bedroegen in:

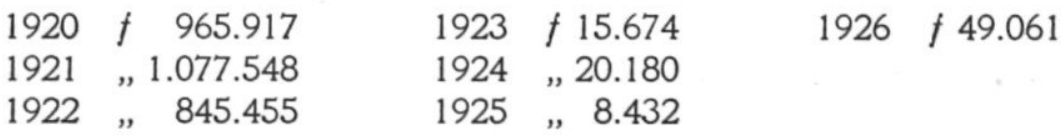

Dergelijke buitengewone heffingen treft men ook aan in de jaren 1931 en 1932, onderscheidenlijk bedragende $f 12.968$ en $f 210.738$.

Brengt men deze ontvangsten in mindering van de bedragen, genoemd in Staat IV der vermelde bijlage ${ }^{1}$ ), dan komt men tot onderstaande cijfers:

\begin{tabular}{|c|c|c|c|c|c|}
\hline 1920 & $f 2.045 .015$ & 1925 & $f 3.017 .824$ & 1930 & $f 2.845 .877$ \\
\hline 92 & 1.917 .189 & 1926 & 2.971 .892 & 1931 & , 2.561.569 \\
\hline 92 & , 1.814 .236 & 1927 & 2.903.545 & 1932 & „2.214.622 \\
\hline 92 & , 2.402.401 & 1928 & 2.999 .332 & & \\
\hline & , 2.570.848 & 1929 & 2.862 .367 & & \\
\hline
\end{tabular}

Op gelijke wijze de inkomsten uit „Andere middelen” beziende, blijkt dat in de totalen, voorkomende op Staat IV der genoemde bijlage voor de jaren 1923, 1924, 1925 en 1926 als toevallige baten zijn opgenomen uitkeeringen uit de Nederlandsche Oorlogswinstbelasting, onderscheidenlijk bedragende $f 231.330, f 15.116$, $f 4.900$ en $f 980$. Voorts, dat in het jaar 1923 onder ,Verschillende ontvangsten" was geboekt $f 75.325$ als terugbetaling door de Norsk Aluminum Company voor bauxiet-onderzoek en dat in 1926 het middel „Huren, erfpachten enz.” $f 19.550$ bevatte voor verkoop van de plantage Margarethenburg en $f 40.000$ als 1e termijn-verkoopsom van Slootwijk, terwijl in het middel „Verschillende ontvangsten" van dat jaar begrepen was $f 247.997$

1) De cijfers over de tusschenliggende jaren zijn thans bijgevoegd. 
wegens verrekening van de bijdragen van de opgezetenen van den Corantijnpolder.

In 1927 is verder onder het middel „Huren, erfpachten enz.” opgenomen $f 141.241$ wegens saldo verkoopsom van Slootwijk en ten slotte onder het middel „Verschillende ontvangsten" van 1932 $f 80.634$ wegens tijdelijke salariskorting der ambtenaren.

Brengt men tot het verkrijgen eener juiste vergelijking der geregelde inkomsten, deze correcties aan, dan krijgt men de volgende cijfers:

\begin{tabular}{|c|c|c|c|c|c|c|c|}
\hline 1920 & 496.775 & 1925 & $f$ & 548.654 & 1930 & $f$ & 474.256 \\
\hline 1921 & 462.390 & 1926 & & 534.634 & 1931 & , & 352.587 \\
\hline 192 & 446.259 & 1927 & & 561.689 & 1932 & ” & 261.019 \\
\hline 192 & 497.931 & 1928 & , & 402.727 & & & \\
\hline 192 & 502.876 & 1929 & & 370.709 & & & \\
\hline
\end{tabular}

Het totaal van „Belastingen” en „Andere middelen” tezamen wordt dan:

\begin{tabular}{|c|c|c|c|c|c|}
\hline 1920 & $f 2.541 .790$ & 1925 & $f 3.566 .478$ & 193 & $f 3.320 .133$ \\
\hline 1921 & 2.379 .579 & 1926 & 3.506 .526 & 193 & 2.914 .156 \\
\hline 922 & , 2.260.495 & 1927 & , 3.465 .234 & 193: & 2.475 .641 \\
\hline 92 & , 2.900.332 & 1928 & , 3.402 .059 & & \\
\hline & , 3.073 .724 & 1929 & , 3.233 .076 & & \\
\hline
\end{tabular}

Een scherpe daling in 1927, vergeleken bij 1926, waarop schrijver de aandacht vestigt, bestaat er dus niet. Ook niet indien men de cijfers der totale inkomsten des lands over die jaren beschouwt. Deze bedroegen onderscheidenlijk $f$ 4.750.997 en $f$ 4.665.277. In de ontwerpbegrooting 1929 was daarbij de volgende beschouwing gesteld:

„Vergeleken bij 1926 blijkt de opbrengst der middelen in 1927 „f 85.720 minder te bedragen. Bij de beschouwing van dit cijfer „moet er evenwel rekening mede worden gehouden, dat in 1926 „werden geboekt $f 49.061$ en $f 54.264$ onderscheidenlijk wegens „buitengewone inkomstenbelasting en opbrengst landskoffie„onderneming Slootwijk, welke middelen sedert vervallen zijn. „Trekt men deze af, dan blijkt het eindcijfer 1927 iets hooger te „zijn dan 1926 ( $f$ 17605). Bovendien is de grondrente in afwach„ting eener regeling der opschorting, niet geind ( $f$ 13000). Voorts "stonden de ontvangsten in 1927 onder den invloed der droogte "1925/1926."

Indien men uit de geregelde inkomsten uit „Belastingen” en „Andere middelen" een conclusie ten opzichte van den economischen toestand zou willen trekken, zou het deze zijn dat die in- 
komsten stegen tot en met 1925, daarna geleidelijk zijn gedaald en sterk zijn gedaald in 1931 en 1932 (crisisjaren). De geleidelijke daling is voorts te verklaren uit de gevolgen der droogte 1925/1926, waardoor de inkomstenbelasting 1927 alreeds meer dan een ton minder bedroeg dan in 1925 (tevens ongeveer het verschil tusschen de totalen van 1925 en 1927), voorts uit een beduidende verlaging der concessierechten en retributie voor balata tot steun aan het bedrijf, tengevolge waarvan in 1928 rond $f 162.000$ minder dan in 1927 en in 1929 wederom $f 32.000$ minder dan in 1928 werd ontvangen, terwijl bovendien in 1929 aan de koloniale kas de uitkeering uit de winst van de Surinaamsche Bank (rond $f 34.000$ ) ontviel. In 1930, toen de rechten op balata, wijl er een opleving van de marktprijs scheen te zijn, weder werden verhoogd, stegen onmiddellijk 's Lands inkomsten uit „Belastingen” en „Andere middelen” met nagenoeg een ton. Dit was het jaar, waarvan in de Memorie van Toelichting der ontwerp-begrooting 1932 werd gezegd:

„Het jaar 1930 was voor Suriname ,in tegenstelling met hetgeen elders gezien wordt, in menig opzicht ,iets gunstiger dan het „jaar 1929.

„De uitvoerwaarde bedroeg $f 8.390 .000$ tegen $f 7.947 .000$ in „het voorafgaande jaar. Van de 7 hoofdproducten (bauxiet, kof„fie, balata, suiker, hout, rijst en goud) bleef de uitgevoerde hoe„,veelheid bij suiker gelijk, bij alle andere nam deze toe in ver"gelijking met 1929. Koffie en suiker vertoonden een daling in „de uitvoerwaarde, de andere vijf hoofdproducten een stijging, „het sterkst bij de rijst, die van $f 45.000$ op $f 234.000 \mathrm{kwam}$.

„Ook de invoer toonde nog geen invloed van de malaise; het ,invoerrecht bracht in 1930 zelfs enkele duizenden guldens meer „op dan in 1929.

,'s Lands middelen, hoewel $f 300.000$ achterblijvend bij de ra„ming, brachten in 1930 meer op dan in de twee voorafgaande „,jaren en voor het eerst sedert 1926 maakte de teruggang der „opbrengsten plaats voor eenigen vooruitgang; de opbrengst „was in $1930 f 147.000$ hooger dan in 1929.

Tegenover de door Schr. uit de cijfers geconcludeerde daling wordt dan gesteld het feit, dat ,alle belastingen sedert 1920 verhoogd zijn." Dit is juist, voor wat verschillende belastingen betreft, niet alle; zelfs is ten deze te wijzen op de geneeskundige belasting, die geheel werd opgeschort, in 1931 dan ook nog slechts geringe inkomsten uit aanslagen van vorige jaren opleverde en in 
1932 niets meer opbracht. Wijst echter Schr. op belastingverhoogingen, dan mag niet nagelaten worden mede te deelen, gelijk hierboven reeds is geschied, dat van „Andere middelen” in de jaren 1928, 1929 en 1931 de rechten op de exploitatie van balata belangrijk werden verlaagd, tengevolge waarvan de inkomsten zéér terugliepen.

Ten aanzien van de ontvangsten ,wegens verleende diensten en uit de bedrijven" lezen wij in het aangehaald artikel het volgende:

„Geeft de loop van 's Lands overheids-ontvangsten een weinig „gunstigen indruk van de ontwikkeling van de draagkracht van „de bevolking, een gelijken indruk krijgt men bij vergelijking der „cijfers van ontvangst wegens verleende diensten en uit de be„drijven.

„Deze bedroegen n.1. in $1920 f 1.823 .649$, in $1925 f 1.668 .352$, in „1930 $f 1.276 .200$ en volgens de voorloopige cijfers van 1932 nog „slechts $f 1.104 .070$, terwijl raadpleging der cijfers van de tus„schenliggende jaren 1925-1930 eveneens aanwijst, dat de daling „in deze categorie van ontvangsten reeds eenige jaren vóór de „wereldcrisis uitbrak, was ingetreden.

„Per saldo komen wij dus, ondanks een bevolkingstoeneming „van $27 \%$ en van het verhoogen van alle belastingen tot een te„ruggang, vergeleken bij 1920 van $21 \%$ in de Overheidsontvang„sten en van $39 \%$ in de ontvangsten wegens verleende diensten „en uit de bedrijven, terwijl het totaal van alle ontvangsten te„zamen van $f 5.331 .356$ tot $f 3.870 .813$ of met $27 \%$ terugging.

„Deze cijfers laten geen ruimte voor een gunstig oordeel om„trent de economische ontwikkeling van Suriname sedert 1920".

Tot het verkrijgen van een volledig beeld zal ik de door Schr. niet genoemde cijfers voor 1926, 1927, 1928 en 1929 alsnog bijvoegen. Men krijgt dan als ontvangsten „wegens verleende diensten en uit de bedrijven", volgens de Staten IV der bijlagen van de betrokken begrootingen de volgende bedragen:

$\begin{array}{llllll}1920 & f 1.823 .649 & 1927 & f 1.347 .897 & 1930 & f 1.276 .200 \\ 1925 & \# 1.168 .352 & 1928 & \# 1.174 .536 & 1932 & \# 1.104 .070 \\ 1926 & \# 1.198 .352 & 1929 & \# 1.210 .942 & & \end{array}$

Ter beoordeeling van de draagkracht der bevolking dient men weer, gelijk hierboven geschiedde, na te gaan, waaruit die totalen zijn opgebouwd. En dan ziet men, dat in de cijfers voor 1920 en 1925 onderscheidenlijk zijn begrepen: 
1920 terugbetaling door het Immigratie-fonds van uit 's Lands kas ontvangen voorschotten $f 772.946$.

rente van de door het Immigratie-fonds uit 's Lands kas ontvangen voorschotten $f 117.286$.

opbrengst der grondrente, terzake van kwijtschelding van vorderingen wegens verleende voorschotten voor de bacovencultuur en rente daarop $f$ 14.495. Totaal dus $f 904.727$.

1925 terugbetaling door het Immigratiefonds van uit 's Lands kas ontvangen voorschotten $f$ 81.556.

rente van de door het Immigratiefonds uit 's Lands kas ontvangen voorschotten $f 270.071$.

opbrengst der grondrente, terzake van kwijtschelding van vorderingen wegens verleende voorschotten voor de bacovencultuur en rente daarop: $f 21.258$.

Totaal alzoo $f 372.885$.

Voorts behoorden in 1920, 1925 en 1926 tot deze ontvangsten onderscheidenlijk $f 18.829, f 143.991$ en $f 54.264$ van 's Lands koffieonderneming Slootwijk en werden in 1927, 1928 en 1929 onder de totalen begrepen achtereenvolgens $f 140.371, f 5.006$, en $f 6.700$ wegens hoofdgeld voor onder contract verbonden immigranten, allen bedragen die niet kwamen ten bate van den gewonen dienst.

Brengt men deze correcties aan, dan worden de cijfers:

$\begin{array}{llllll}1920 & f 900.093 & 1927 & f 1.207 .166 & 1930 & f 1.276 .200 \\ 1925 & , 1.151 .476 & 1928 & , 1.169 .530 & 1932 & \# 1.104 .070 \\ 1926 & \# 1.144 .088 & 1929 & \# 1.204 .242 & & \end{array}$

Uit deze cijfers blijkt geenszins, dat de daling in de geregelde inkomsten dezer categorie reeds eenige jaren vóór de wereldcrisis uitbrak, was ingetreden, gelijk Schr. meende te kunnen constateeren.

Het jaar 1932 maakt een slecht figuur, maar toen was de crisis op volle hoogte.

Zoo kan men dus, als men de cijfers niet ontleedt, gemakkelijk tot onjuiste conclusies komen, hetgeen wel zeer scherp wordt gedemonstreerd in de op bldz. 370 der Econ. en Stat. berichten voorkomende uitspraak, luidende: „terwijl het totaal van alle ontvangsten tezamen van $f 5.331 .356$ (in 1920) tot $f 3.870 .813$ (in 1932) of met $27 \%$ terugging." Voor de beoordeeling van den economischen ontwikkelingsgang mogen n.m.m. deze cijfers niet zonder meer naast elkaar worden gesteld, want in de inkomsten van 1920 waren begrepen $f 772.946$ wegens door het Immigratie- 
Fonds terugbetaalde voorschotten, $f 117.286$ wegens rente op deze voorschotten en $f 965.917$ wegens buitengewone heffingen. Wil men niet het totaal bedrag der buitengewone heffingen als toevallige bate beschouwen, dan moet men dit toch zeker doen met de opbrengst der daartoe behoorende buitengewone inkomstenbelasting ( $f 333.581)$. Brengt men deze in de le, 2e en $4 \mathrm{e}$ plaats genoemde bedragen in mindering, dan blijkt de feitelijke opbrengst in 1920 te zijn $f 4.107 .543$, die vergeleken kan worden met die van het crisis-jaar 1932 ad $f 3.870 .813$. In 1930, alzoo vóórdat de crisis in Suriname ernstig merkbaar was, bedroeg de zuivere opbrengst nog $f$ 4.590.317.

De betrekkelijke waarde van soortgelijke vergelijkingen blijkt wel zeer duidelijk, indien men in plaats van de jaren 1920 en 1932 neemt de jaren 1919 en 1930 . Immers in 1919 bedroeg de werkelijke opbrengst der gewone middelen $f 3.846 .548$, in 1930 $f$ 4.590.317, alzoo een verschil van $f 743.769$ ten voordeele van 1930 .

De beschouwing der verschillende cijfers heeft den Schr. gediend om te betoogen, dat bij een zóódanigen teruggang in de inkomsten het Bestuur in de ter sprake gebrachte periode bezuinigingen heeft moeten aanbrengen, die nadeelig waren voor de ontwikkeling des lands.

Ik moet tegen deze uitspraak bezwaar maken.

Niet omdat ik met Schr. van meening verschil over de moeilijkheden, die er verbonden zijn aan het tot ontwikkeling brengen van het gewest, waai de ter beschikking staande geldmiddelen aan een grens gebonden zijn en de belangstelling van particuliere ondernemers maar niet tot daden komen kan, maar omdat ik de aangehaalde uitspraak een miskenning acht van hetgeen in werkelijkheid heeft plaats gehad. Er is aanmerkelijk bespaard op personeeele uifgaven en op werkfondsen, maar steeds alleen dáár, waar naar de meening van het Bestuur geen nadeel werd toegebracht aan de organen, die de ontwikkeling kunnen bevorderen. Bovendien zijn er in den loop der genoemde periode (behalve in de ernstigste crisisjaren) nog beduidende bedragen gevoteerd voor nieuwe productieve uitgaven.

Schr. haalt, tot staving zijner meening, het in de M. v. A. der begrooting 1930 door den Gouverneur uiteengezette welvaartsplan aan en toetst dit aan de in de periode 1920-1932 ten behoeve der onderdeelen van dit plan beschikbaar gestelde gelden. Ik zal niet ingaan op de vraag, in hoeverre het juist is om, waar over dit plan in 1930 werd gesproken, terug te grijpen tot 1920 , maar ik wil Schr. daarin volgen. 
In de eerste plaats wordt dan becijferd, wat is uitgegeven in 1920, 1925, 1930 en 1932 ten behoeve van immigratie en kolonisatie t.w. voor den aanvoer van contractanten, voor de uitkeering van premies aan vrije immigranten, die afzien van hun recht op terugreis, voor landvoorziening ten behoeve van den klein-landbouw en voor aanleg en onderhoud van vestigingsplaatsen. Daarvoor komt Schr. tot een totaal in 1920 van $f 1.183 .903$, in $1925 f 667.342$, in $1930 f 259.462$ en in $1932 f 114.293$. Maar voor de vergelijking worden deze cijfers gecorrigeerd omdat in 1920 en 1925 de bedragen voor aanvoer van contractanten en een gedeelte der aan vrije immigranten uitgekeerde premies met leeningsgeld werden betaald, zoodat deze uitgaven niet rechtstreeks op de koloniale kas drukten. M.i. is deze opvatting niet juist; indien men vraagt: wat is er nu in die jaren aan immigratie en kolonisatie gedaan, moet het antwoord niet afhankelijk worden gesteld van de wijze van financieren.

Maar de methode van Schr. volgend, moet er op worden gewezen, dat de toegepaste aftrek voor de jaren 1920 en 1925 niet juist is, want in die jaren werden niet de premies voor een gedeelte, maar ten volle met leeningsgeld betaald en geschiedde ditzelfde met de uitgaven voor landvoorziening voor den kleinlandbouw. Eerst in 1930 en 1932 drukten de uitgaven voor al deze voorzieningen, behalve voor den aanvoer van contractanten, rechtstreeks op de koloniale kas; de aanvoer in 1930 werd nog met leeningsgeld betaald, in 1932 heeft geen aanvoer plaats gehad. Hadde in 1932 wel aanvoer plaats gehad, dan zou ook de koloniale kas de kosten daarvan hebben gedragen, wijl het in de bedoeling lag de schuld niet meer te doen oploopen.

Indien men met het vorenstaande rekening houdt, krijgt men geheel andere uitkomsten. En beschouwt men, hetgeen in deze jaren ten aanzien dezer onderwerpen is geschied, op zich zelf dus zonder rekening te houden met de wijze van betalen, dan krijgt men het volgende:

Aangevoerd zijn de volgende aantallen immigranten:

in $\begin{array}{rcrrrrrr}1920 & 3.559 & 1924 & 1.135 & 1928 & 2.323 & 1932 & - \\ 1921 & - & 1925 & 1.713 & 1929 & 837 & & \\ 1922 & 1.975 & 1926 & 1.349 & 1930 & 522 & & \\ 1923 & 657 & 1927 & 1.724 & 1931 & 455 & & \end{array}$

Daarbij moet nog worden aangeteekend, dat als onderdeel van een bepaalde politiek, in de jaren 1930 en 1931 uitsluitend vrije Javaansche gezinnen zijn aangevoerd, teneinde met deze wijze 
van immigratie een proef te nemen en voorts dat de geringere aanvoer in die jaren en het geheel achterwege blijven van aanvoer in 1932 verband hield met de crisis in de koffiecultuur, die de aanvoer van werkvolk onnoodig maakte.

Voor de andere, met de kolonisatie verband houdende onderwerpen, is uitgegeven:

\begin{tabular}{|c|c|c|c|c|}
\hline & 1920 & 1925 & 1930 & 1932 \\
\hline $\begin{array}{l}\text { Premiën, aan immigranten, } \\
\text { die afzien van recht op te- } \\
\text { rugreis . . . . . . . . . . }\end{array}$ & $f \quad 33.200 f$ & $45.000 f$ & $44.000 \mid f$ & 60.600 \\
\hline $\begin{array}{l}\text { Landvoorziening v. d. klein- } \\
\text { landbouw . } \cdot \cdot \cdot \cdot \cdot \cdot \cdot \\
\text { Aanleg en onderhoud vesti- }\end{array}$ & 186.458 & 54.042 & 92.562 & 5.117 \\
\hline gingsplaatsen . . . . . . & 50.000 & 45.000 & 53.000 & 48.576 \\
\hline Beheer van vestigingsplaatsen & 20.269 & 24.490 & 31.222 & 28.554 \\
\hline
\end{tabular}

Hierbij moet worden aangeteekend, dat de hooge uitgaven voor landvoorziening in 1920 t.w. $f 186.458$ op rekening komen van den aanleg van een gedeelte van den Corantynpolder en den bouw van een sluis (tezamen vorderend $f 157.400$ ) terwijl bij de lage uitgaven voor hetzelfde doel in 1932 ( $f$ 5.117) in de Ontwerpbegrooting staat toegelicht: „In verband met de tijdsomstandigheden en in afwachting van de komst van den irrigatie-ingenieur zijn de werkzaamheden beperkt."

Thans komen we bij de uitgaven voor den landbouw.

Schr. somt daarvoor de volgende bedragen op:
1920 f 221.878
$1930 f 192.266$
$1925,212.351$
$1932,171.902$

Deze cijfers zijn ontleend aan bijlage I Overzicht der Landsuitgaven. $\mathrm{Zij}$ luiden daar:

$\begin{array}{llll}1920 & f 221.878 & 1930 & f 223.488 \\ 1925,212.351 & 1932 & \text {,200.456 }\end{array}$

De cijfers voor 1930 en 1932 zijn door Schr. verminderd onderscheidenlijk met $f 31.222$ en $f 28.554$ voor „Beheer van landsvestigingsplaatsen en stalweiden", maar dit is niet gedaan voor de jaren 1920 en 1925, alhoewel bedoelde uitgaven ook onder de totalen voor die jaren begrepen zijn. Doet men dit, 
dan krijgt men de volgende cijfers, die voor vergelijking kunnen dienen.

$\begin{array}{rrr}1920 f 201.609 & 1930 & f 192.266 \\ 1925,187.860 & 1932 & \ldots 171.902\end{array}$

Bij de beschouwing dezer cijfers moet men in het oog houden, dat in de cijfers voor 1920 en 1925 nog beduidende bedragen (onderscheidenlijk $f 16.342$ en $f 9.388$ ) begrepen zijn voor landbouwonderwijs, waarvoor in 1930 en 1932 achtereenvolgens slechts $f 1200$ en $f 1100$ werd besteed. Dat in latere jaren zooveel minder voor dat doel is uitgegeven, is niet uitsluitend toe te schrijven aan bezuinigingsmotieven, maar aan het feit, dat de resultaten van dat onderwijs zeer teleurstellend waren. Zoo vermeldde de M. v. T. begrooting 1926: „De laatste drie jaren hebben zich geen candidaten voor het examen landbouwkunde aangemeld." Het Surinaamsch Verslag 1932 vermeldt op bldz. 53 de redenen, waarom de belangstelling in dit onderwijs uitbleef en de geheele organisatie fiasco leed.

Hier gaven dus geen bezuinigingsmotieven den doorslag.

Voorts moet er ten aanzien der uitgaven nog op worden gewezen, dat in 1930 bovendien is uitgegeven (opgenomen onder „Onvoorzien") $f 35.437$ wegens participatie van het Gouvernement in het kapitaal van de N. V. Westindische Maatschij. tot exploitatie van de koffie-installatie systeem Fernandes en $f 10.000$ uitkeering aan de Kamer van Koophandel voor den afzet van Surinaamsche producten op Curaçao, waarvoor in 1932 zelfs $f 28.300$ is besteed.

Het is wellicht belangwekkend de verschillen in de personeelsorganisatie na te gaan tusschen de jaren 1920 en 1932, waarvan Schr. getuigde: „Van het in 1920 nog vrij uitgebreide landbouw„departement is nog slechts het landbouwproefstation overge„bleven."

Dit zou den indruk kunnen wekken, alsof hier aan afbraak moet worden gedacht.

Aan deskundig personeel telde het departement van landbouw, nijverheid en handel in 1920:

1 directeur van landbouw, nijverheid en handel.

1 landbouwassistent.

4 landbouwleeraren.

1 plantkundige, directeur van het proefstation.

1 landbouwscheikundige.

1 entomoloog. 
1 directeur cultuurtuin.

1 opzichter cultuurtuin.

Het overige, op de begrooting van 1920 voorkomende personeel, was bestemd voor landbouwonderwijs of komt (zooals de veearts en het personeel voor het beheer dr landsvestigingsplaatsen) op de begrooting van 1932 onder andere hoofdstukken voor.

In 1932 waren als deskundigen aan het toen alleen bestaande landbouwproefstation verbonden:

1 plantkundige, directeur van het landbouwproefstation en van den cultuurtuin.

1 plantkundige.

i landbouwconsulent (in het laatste gedeelte des jaars naar O.I. teruggekeerd).

1 entomoloog.

1 landbouwscheikundige.

1 tuinbouwkundige.

1 opzichter cultuurtuin.

2 landbouwleeraren.

De verminderde werkingsmogelijkheid van het proefstation, waarvan door Schr. gewag wordt gemaakt onder aanhaling van een uitspraak van den directeur van dat station, gedaan in Januari 1933 moet zóó worden bezien, dat in verband met het óók in Suriname op volle hoogte zijn van de crisis, het crediet voor proefnemingen voor dat jaar was teruggebracht tot $f 10.000$. In het jaar 1932 en de daaraan voorafgegane jaren (en over deze periode heeft schr. zijn beschouwingen gegeven) was dat crediet $f 30.000$, in 1929 zelfs $f 40.000$.

Als derde onderdeel wordt genoemd het boschwezen.

Inderdaad is in den loop der jaren en in het bijzonder na 1929 het boschwezen tot zeer bescheiden afmetingen teruggebracht. Ten aanzien daarvan moet evenwel worden aangeteekend, dat niet algemeen het inzicht werd gedeeld nopens de doelmatigheid van het boschtoezicht. Dat heeft aanleiding gegeven tot een van Overheidswege doen instellen van een onderzoek ter plaatse, waaruit inderdaad bleek, dat een wijziging in de organisatie kon worden aangebracht, die beduidend minder personeel vereischte. Alhoewel dus de drang naar vermijding van het doen van overbodige uitgaven zeker niet vreemd was aan het besluit de credieten voor het boschtoezicht te verminderen, zoo was het toch ook het nut van het boschtoezicht zelf, waaraan door het Bestuur geen waarde voor de exploitatie der bosschen werd gehecht. Bij de behandeling van het betrokken voorstel in de koloniale Staten 
deelde de voormalige directeur van het departement van landbouw mede zes jaren lang als chef van de boschpolitie nauwe aanraking met dit personeel te hebben gehad, doch van meening te zijn, dat het kan worden gemist.

Wat overigens het boschwezen betreft, moet er nog op worden gewezen, dat in de jaren 1926 en 1927 een deskundige op het gebied van boschexploitatie in Suriname gedetacheerd is geweest teneinde omtrent de exploitatie-mogelijkheden aan den Minister van Kolonien te rapporteeren. De aanwijzingen in dat rapport om tot een groot-bedrijf te geraken zijn ook tot uitvoering gekomen. Daarnevens deed het Bestuur in 1930 een poging om weder de beschikking te krijgen over een houtvester; de daartoe op de ontwerp-begrooting gebrachte post is echter door de Koloniale Staten niet aanvaard.

Als vierde onderdeel van het welvaartsplan wordt genoemd de hygienische verzorging der bevolking. Gezegd wordt, dat het bezwaarlijk is hiervoor cijfers te verstrekken, omdat de begrootingen van de jaren vóór 1927 niet afzonderlijk de hoofden: „Openbare gezondheidsdienst in het algemeen" en "Hygienische dienst" vermelden. Toch is er m.i .een weg, die leiden kan tot het verkrijgen van een inzicht in hetgeen ten deze in de genoemde periode is gedaan.

De totale uitgaven voor den geneeskundigen dienst (VIIde Afdeeling der Begrooting) bedroegen in de jaren:

1920 f 753.317

$1925,789.278$

$1930+763.537$

$1932,766.263$

In deze totale uitgaven is een post begrepen, waarvoor de uitgaven geleidelijk aanzienlijk zijn gedaald t.w. de verpleging. van burgerpersonen in het militair hospitaal. Deze post bedroeg in:
$1920 f 304.020$
$1930 f 169.680$
$1925,325.000$
$1932,140.000$

Daartegenover staat, dat in verband met de toename der gestichtsbevolking de uitgaven voor het krankzinnigengesticht en die voor de verpleging der lepralijders (subsidies aan particuliere instellingen inbegrepen) regelmatig stegen. $\mathrm{Zij}$ bedroegen in:
$1920 f 189.160$
1930 f 251.219
$1925,218.912$
$1932,263.500$

De daling der uitgaven voor de verpleging van burgerpersonen 
in het militair hospitaal bedroeg in genoemde periode $f 304.020$ $f 140.000=f 164.000$; de stijging der kosten van de gestichtsbevolking bedroeg $f 263.500-f 189.160=f 74.340$. Er zou dus een voordeelig saldo moeten overblijven van $f 164.000-$ $f 74.340=f 89.660$. De totale kosten van den geneeskundigen dienst waren evenwel in $1932 f 12.846$ hooger dan in 1920, hetgeen erop wijst, dat voor de andere onderwerpen van ziekenzorg en ziektevoorkoming geleidelijk meer is uitgegeven. In het Verslag van den Openbaren gezondheidsdienst in Suriname 19301932 lezen wij dan ook onder het hoofd: Slotconclusie betreffende den Staat der Volksgezondheid in Suriname het volgende:

„Een niet genoeg te waardeeren gunstige omstandigheid is, „dat in deze tijden van crisis de dienst ter bestrijding en voor„koming van ziekten ongestoord tot verdere ontwikkeling kon „komen, dat evenmin de individueele ziekenverzorging eenigen "rem is opgelegd. In ommestaande staat zij dit met enkele spre„kende cijfers geillustreerd, die eenerzijds getuigen van een toe„nemende behoefte aan gouvernementssteun, anderzijds ge"tuigenis afleggen van een ongelimiteerde hulpverleening".

Deze slotconclusie wijst, dunkt mij, niet op het onthouden van de voor de behoeften van dezen dienst noodige credieten.

Ten slotte moet hierbij nog worden aangeteekend, dat in de jaren 1929 e.v. uitgaven zijn gedaan (verantwoord onder ,onvoorzien") ten behoeve van de onderzoekingen voor den aanleg eener waterleiding, een werk dat toch zeker ook geacht kan worden in het belang te zijn van de voorkoming van ziekten in het gewest. Wel zouden deze uitgaven, indien de waterleiding tot stand kwam, worden gerestitueerd, voorloopig drukten zij niettemin op de begrooting.

En nu ten slotte de uitgaven voor den aanleg van wegen.

De uitgaven over de door Schr. in beschouwing genomen periode, bedroegen:

$1920 f 155.108$

$1930+263.297$

$1925,131.310$

$1932,302.343$

Van deze totaal-uitgaven bedroegen die, voor den aanleg, de verbetering en het onderhoud der wegen in de districten:

$1920 f 9.500$

1930 f 42.000

1925

$1932,132.000$

waarbij nog moet worden aangeteekend, dat feitelijk het bedrag voor 1930 zou moeten luiden $f 72.000$, wijl in dat jaar voor den 
aanleg van wegen gebruik werd gemaakt van den arbeid van gestraften, waarvan de waarde werd gesteld op $f 30.000$.

$\mathrm{Nu}$ zegt Schr. dat de wegaanleg in de districten den laatsten jaren meer het karakter van werkverschaffing heeft aangenomen dan van een systematische uitvoering als onderdeel van een welvaartsplan, maar deze uitspraak is niet juist. De noodzakelijkheid tot het verschaffen van werk aan werkeloozen heeft er toe geleid om den aanleg van reeds lang tevoren in het oog gevatte wegen in versneld tempo te doen uitvoeren; op de keuze der verbindingen, die in het belang der economische ontwikkeling zouden worden tot stand gebracht, heeft de werkverschaffingszorg niet den minsten invloed uitgeoefend.

Wanneer men dan ten slotte nog in aanmerking neemt, dat in de jaren 1929 en 1930 uitgaven van ruim een ton (de juiste gegevens ontbreken mij) zijn gedaan voor den bouw van een veerdienst bij Paramaribo en een ongeveer even groot bedrag voor de moderniseering van den radiodienst, beiden toch onbetwistbaar in het belang van de economische ontwikkeling des lands, dan vermeen ik, dat het volkomen in strijd is met de feiten, indien men uit den gang van zaken concludeert, dat de bezuinigingsactie, noodzakelijk geworden door het oploopen der uitgaven voor pensioenen en voor onderwijs, gepaard aan het wegvallen van belangrijke inkomsten (als o.a. die uit het balata-bedrijf en die uit de inkomstenbelasting, wegens lage prijzen van koffie en suiker, alsmede die uit de invoerrechten, wegens geringeren aanvoer en daling der prijzen voor de naar waarde belaste goederen) takken van dienst heeft getroffen, die de economische ontwikkeling kunnen bevorderen.

Veel onnoodigs is in den loop der jaren afgesneden; op dit gebied moet en kan nog geleidelijk worden voortgegaan. Het oploopen van den rentelast en van den pensioenlast is thans geremd. Het onderwijs, in den vorm waarin het bestaat, voor de maatschappelijke structuur veel te hoog opgevoerd, zal eerst tot dragelijke proporties zijn teruggebracht, indien de leerplicht (die in O.-Indië en op Curaçao niet bestaat) wordt afgeschaft en - behalve door onvermogenden - wordt bijgedragen aan de kosten.

Indien dan daarnaast wordt voortgegaan met het steunen van ernstige ondernemers in het tot ontwikkeling brengen van cultures, mijn- en boschbedrijven, dan is er m.i. geen reden om aan de toekomst te wanhopen. Een nieuwe commissie en een nieuw plan, gelijk de heer van Traa noodig acht, zullen slechts met één vermeerderen het aantal commissies en plannen, dat alreeds even groot is als het aantal rivieren van dit West-Indische gewest. 